\title{
Preparation of Amphiphilic Sorbitan Monoethers through Hydrogenolysis of Sorbitan Acetals and Evaluation as Bio-Based Surfactants
}

\author{
Charlotte Gozlan, ${ }^{a, c}$ Elsa Deruer, ${ }^{a}$ Marie-Christine Duclos, ${ }^{a}$ Valérie Molinier, ${ }^{b}$ Jean-Marie Aubry, ${ }^{b}$ Andreas Redl, ${ }^{c}$ \\ Nicolas Duguet, ${ }^{a}$ and Marc Lemaire*a
}

\begin{abstract}
Amphiphilic sorbitan acetals have been prepared from sorbitan by acetalisation using linear aliphatic aldehydes or by transacetalisation starting from the corresponding aldehyde diethylacetals. A series of sorbitan acetals has been obtained with $29-81 \%$ isolated yields. It has been shown that these sorbitan acetals exist as a mixture of five-membered and six-membered regioisomers. Hydrogenolysis of the mixtures gave the corresponding sorbitan ethers as a mixture of 3 regioisomers with $55-85 \%$ isolated yields. A one-pot twostep procedure was also optimized from sorbitan giving similar results. The amphiphilic properties of sorbitan acetals and ethers were evaluated and both families exhibit interesting surfactant properties.
\end{abstract}

\section{Introduction}

Surfactants are encountered in many applications such as detergents, cleaning formulations, home and personal care products, pharmaceuticals, paints, textiles, chemicals, and food industries. ${ }^{1}$ More particularly, non-ionic surfactants have gained interest and are progressively overtaking ionic ones. They offer many advantages over the ionic surfactants such as being less skin irritant, exhibiting a usually higher biodegradability, increased stability, formulating flexibility and wider compatibility. From a physical chemistry point of view, they have a lower CMC (Critical Micellar Concentration) than ionic counterparts, are less sensitive to hard water and their properties are weakly affected by electrolytes. Among the nonionic class, carbohydrate-based surfactants have attracted a lot of attention due to their low environmental impact profiles. Indeed, they are obtained from renewable resources in bulk quantities and are usually non-toxic and biodegradable. ${ }^{2,3}$ Moreover, their relatively low prices make them perfectly adequate for industrial applications and some of them have already been commercially produced for a long time ${ }^{4}$ such as sucrose esters, ${ }^{5}$ alkyl polyglucosides (APGs) ${ }^{6}$ and sorbitan esters. ${ }^{7,8}$

Sorbitan fatty acid esters (SFEs), most commonly known under the trademarks of Span ${ }^{\circledR}$ and Tween ${ }^{\circledR}$ (their polyethoxylated derivatives), are eco-friendly renewable surfactants that possess good surface properties and tunable hydrophilic-lipophilic balances (HLB's). ${ }^{9}$ To date, they have found many industrial applications mainly as emulsifiers in food, ${ }^{10}$ pharmaceuticals and cosmetics, ${ }^{11}$ but they have also been used in paints, ${ }^{12}$ explosives and for polymerization processes. However, SFEs could only be used over a limited pH-range due to the vulnerability of the ester link towards hydrolysis in acid or basic conditions. In order to circumvent this problem, another category of carbohydrate-based surfactants has been proposed based on the ether linkage. Indeed, these compounds usually offer increased stability in both acid and basic media that represents a definite asset to widen the scope of applications of such surfactants. Moreover, a recent study on glycerol-derived ethers has shown that these compounds could have a quite low eco-toxicity. ${ }^{13}$ The synthesis of carbohydrate-derived ethers is most often laborious and usually requires protection / deprotection strategies for selectivity reasons. ${ }^{14}$ Moreover, polar solvents such as dimethylformamide (DMF) or dimethylacetamide (DMA) are usually needed to improve the solubility of reagents but their utilization is barely acceptable from ecological and economical points of view. Overall, such approaches suffer from low atom-economies and are no longer suitable in the context of green chemistry. Not surprisingly, the preparation of ethers from unprotected sugar derivatives or related polyols is much more difficult due to the great difference of polarity between reactants. However, efficient catalytic approaches have recently emerged such as palladium-catalysed telomerization of butadiene, palladium-catalysed reductive alkylation (reductive etherification), acid-catalysed hydroalkoxylation and etherification, and ring-opening of epoxides. All these methods have been recently reviewed. ${ }^{15}$

In contrast with the abundant literature concerning sorbitan esters, the access to sorbitan ethers has barely been explored. To the best of our knowledge, only one patent has described the synthesis of sorbitan ethers by reductive alkylation of sorbitol. ${ }^{16}$ However, neither yields nor selectivities for the formation of monoethers have been reported in this document.

For several years, our laboratory has been interested in developing green methodologies for the catalytic reductive $N$ or $O$-alkylation of weak nucleophiles using hydrogen as a clean reductant. ${ }^{17,18}$ These methods led to the preparation of ether surfactants mainly based on polyols, such as glycerol, ${ }^{19}$ and methyl $\alpha$-D-glucopyranoside. ${ }^{20}$ We report here an economically and environmentally-friendly route to sorbitan ethers from sorbitol through hydrogenolysis of sorbitan acetals (Scheme 1). Moreover, we also describe the physicochemical properties of both ethers and acetal intermediates.

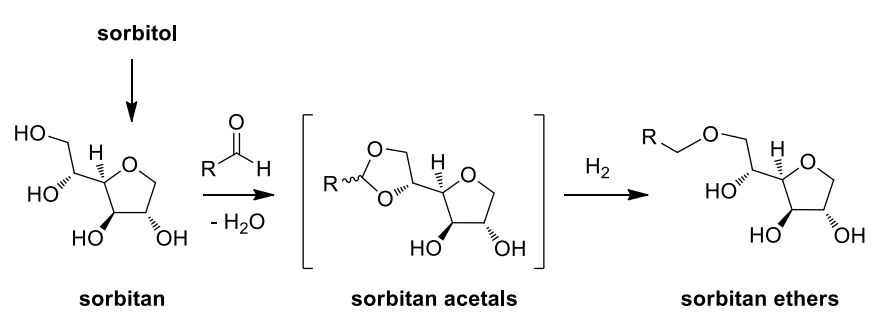

Scheme 1. Preparation of sorbitan ethers from sorbitan. 


\section{Results and discussion}

We have previously reported the direct reductive alkylation of alcohol, diol and triol such as glycerol using aldehydes, acids or esters as alkylating agents and using hydrogen as a clean reductant for the preparation of the corresponding monoethers. In order to push forward this methodology, we first attempted the direct reductive alkylation of D-sorbitol - a hexol produced from hydrogenolysis of glucose - using our standard conditions. Thus, sorbitol $\mathbf{1}$ (2 equiv.) was treated with valeraldehyde (1 equiv.) in the presence of $5 \%-\mathrm{Pd} / \mathrm{C}(1 \mathrm{~mol} \%)$, camphorsulfonic acid (CSA, $10 \mathrm{wt} \%$ ) and hydrogen (35 bar) at $130^{\circ} \mathrm{C}$ for 15 hours. Under these conditions, 1,4-D-sorbitan 2 and isosorbide 3 were obtained as a 48:52 mixture resulting from two consecutive dehydration of sorbitol. Unfortunately, only traces of sorbitan ethers have been detected by GC-MS (Scheme 2).

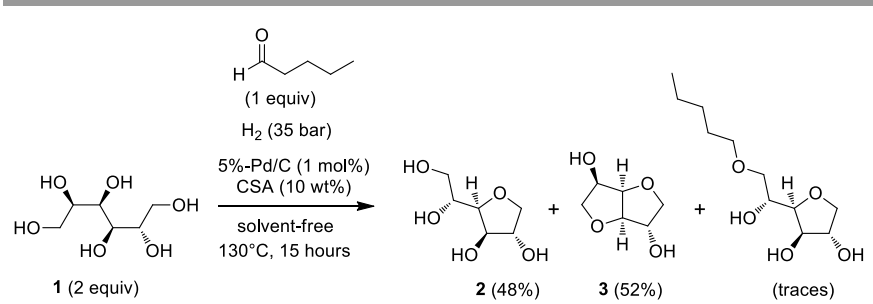

Scheme 2. Direct reductive alkylation of sorbitol.

As the dehydration of sorbitol was inevitable under these conditions, we decided to prepare sorbitan ethers using sorbitan as starting material. Moreover, we chose to prepare these ethers by an indirect reductive alkylation pathway, involving acetal formation and subsequent hydrogenolysis, in order to characterize and study the physicochemical properties of acetal intermediates.

\section{Preparation of 1,4-D-sorbitan}

1,4-D-Sorbitan could be directly prepared by monodehydration of sorbitol ${ }^{21}$ under acidic conditions. The main challenge of this reaction lies in the control of the production of unwanted isosorbide, product of dehydration of sorbitan. The preparation of sorbitan was first investigated under hydrogen pressure. Indeed, Holladay et al. have shown that hydrogen could limit the formation of colored by-products resulting from degradation (or polymerization) of sugars. ${ }^{22}$ Moreover, these conditions are close to those reported for the direct reductive alkylation. Thus, sorbitol 1 was heated at $140{ }^{\circ} \mathrm{C}$ under 50 bars of hydrogen in the presence of CSA $(0.1 \mathrm{~mol} \%)$. Under these conditions, the conversion reached $73 \%$ and HPLC analysis ${ }^{23}$ revealed a 80:20 mixture of 1,4-D-sorbitan 2 and isosorbide 3 (Table 1, Entry 1). The replacement of CSA by an ionexchange resin such as Amberlyst 15 (A15, 0.1 wt\%) gave an improved $83 \%$ conversion but a lower selectivity (Table 1 , Entry 2). Increasing the loading to $10 \mathrm{wt} \%$ slightly improved the conversion but isosorbide was obtained as the major product (Table 1, Entry 3). Without hydrogen pressure, CSA $(0.1 \mathrm{~mol} \%)$ gave a similar conversion $(79 \%)$ but the sorbitan /isosorbide ratio dropped to 60:40 (Table 1, Entry 4). Conversely, the use of para-toluenesulfonic acid ( $p$-TSA, 0.1 mol\%) led to sorbitan with a high selectivity of $92 \%$ (Table 1 , Entry 5). Finally, the use of $3 \mathrm{M} \mathrm{H}_{2} \mathrm{SO}_{4}(0.2 \mathrm{~mol} \%)$ gave the best results with an excellent selectivity towards 1,4-sorbitan (93\%) while preserving a decent conversion (Table 1, Entry 6).
Table 1. Preparation of sorbitan. ${ }^{a}$

\begin{tabular}{|c|c|c|c|c|c|c|}
\hline & 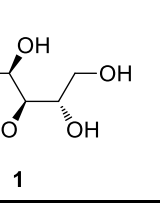 & $\begin{array}{c}\text { Acid catalys } \\
\text { solvent-free } \\
140^{\circ} \mathrm{C}\end{array}$ & $\mathrm{HC}$ & 2 & + & 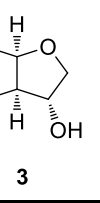 \\
\hline Entry & Cat. & $\begin{array}{c}\text { Loading } \\
(\mathrm{mol} \%)\end{array}$ & $\begin{array}{c}\mathrm{H}_{2} \\
\text { (bar) }\end{array}$ & $\begin{array}{l}\text { Time } \\
\text { (h) }\end{array}$ & $\begin{array}{c}\text { Conv. } \\
(\%)\end{array}$ & $\begin{array}{c}\text { Ratio }^{c} \\
\mathbf{2 : 3} \\
(\%)\end{array}$ \\
\hline 1 & CSA & 0.1 & 50 & 15 & $73(33)^{e}$ & $80: 20$ \\
\hline 2 & A15 & $0.1^{d}$ & 50 & 24 & 83 & $72: 28$ \\
\hline 3 & A 15 & $10^{d}$ & 50 & 24 & 86 & $19: 81$ \\
\hline 4 & CSA & 0.1 & - & 15 & 79 & $60: 40$ \\
\hline 5 & $p$-TSA & 0.1 & - & 2 & 71 & $92: 8$ \\
\hline 6 & $3 \mathrm{M} \mathrm{H}_{2} \mathrm{SO}_{4}$ & 0.2 & - & 15 & $66(56)^{e}$ & 93:7 \\
\hline
\end{tabular}

${ }^{a}$ Reaction conditions: $110 \mathrm{mmol}$ of sorbitol, $140{ }^{\circ} \mathrm{C}$. ${ }^{b}$ Determined by ${ }^{1} \mathrm{H}$ NMR. ${ }^{c}$ Determined by HPLC. ${ }^{d} \mathrm{wt} \% .{ }^{e}$ Isolated yield in brackets.

From a practical point of view, unreacted sorbitol could be easily removed by filtration of the reaction mixture but isosorbide is much more difficult to eliminate during the purification step. Thus, the use of $3 \mathrm{M} \mathrm{H} \mathrm{H}_{2} \mathrm{SO}_{4}$ has been privileged for the dehydration of sorbitol on the large scale (1 $\mathrm{kg}$ ). Under these conditions, 1,4-sorbitan 2 has been prepared with $43 \%$ isolated yield and $>98 \%$ purity after recristallisation.

\section{Sorbitan acetals by acetalisation}

With sorbitan in hands, we first investigated the formation of sorbitan acetals by direct acetalisation of sorbitan using valeraldehyde as a model substrate. The molar ratio between reagents was first studied under solvent-free conditions and in EtOH. Thus, sorbitan (neat, 2 equiv) was treated with valeraldehyde in the presence of CSA $(10 \mathrm{~mol} \%)$ at $95{ }^{\circ} \mathrm{C}$ for 15 hours. Under these conditions, the conversion reached $79 \%$ and sorbitan acetals 4 and 5 were recovered with $40 \%$ combined isolated yield (Table 2, Entry 1). No attempt to fully characterize the products has been made at this stage of the study. Increasing the sorbitan / aldehyde molar ratio to $3: 1$ did not significantly improve the product yield (Table 2, Entry 2). These poor results could be explained by the formation isosorbide. Indeed, due to the biphasic nature of the reaction mixture (one sugar phase, one lipid phase), sorbitan could not react with the aldehyde and condensate on itself. As a consequence, the reaction was then investigated in dilute condition. Sorbitan was treated with a stoichiometric amount of valeraldehyde using $\mathrm{EtOH}$ at $80{ }^{\circ} \mathrm{C}$. Under these conditions, a quantitative conversion was obtained and sorbitan acetals $\mathbf{4}$ and 5 were isolated with $58 \%$ isolated yield (Table 2, Entry 3). Considering the fact that some sorbitan diacetal has been observed as by-product, the reaction was carried out using an excess of sorbitan. Increasing the sorbitan/aldehyde ratio to $2: 1$ and 3:1 permitted to improve the isolated yield to 73 and $81 \%$, respectively (Table 2, Entries 4 and 5). 
Table 2. Influence of the molar ratio for the acetalisation of sorbitan with valeraldehyde. $^{a}$

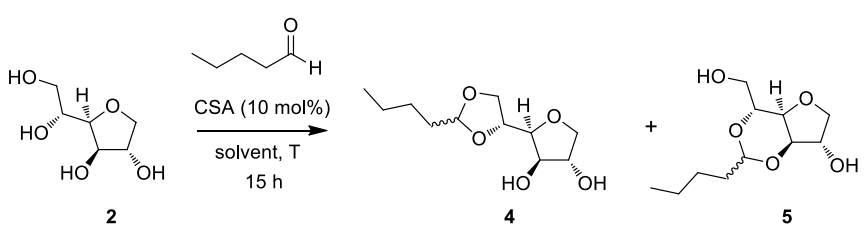

\begin{tabular}{cccccc}
\hline Entry & $\begin{array}{c}\text { Molar ratio } \\
\mathbf{2}: \text { ald }\end{array}$ & Solvent & $\begin{array}{c}\text { Temp. } \\
\left({ }^{\circ} \mathbf{C}\right)\end{array}$ & $\begin{array}{c}\text { Conv. }^{b} \\
(\%)\end{array}$ & $\begin{array}{c}\text { Isolated yield } \\
(\%)\end{array}$ \\
\hline 1 & $2: 1$ & - & 95 & 79 & 40 \\
2 & $3: 1$ & - & 95 & 79 & 43 \\
\hline 3 & $1: 1$ & EtOH & 80 & $>98$ & 58 \\
4 & $2: 1$ & EtOH & 80 & $>98$ & 73 \\
5 & $3: 1$ & EtOH & 80 & $>98$ & 81
\end{tabular}

${ }^{a}$ Reaction conditions: $1 \mathrm{mmol}$ of valeraldehyde, CSA ( $\left.10 \mathrm{~mol} \%\right), 1.4 \mathrm{~mL}$ of solvent if any, 15 hours. ${ }^{b}$ Determined by ${ }^{1} \mathrm{H}$ NMR. ${ }^{c}$ Purification by silica gel chromatography, combined yield of sorbitan acetals $\mathbf{4}$ and $\mathbf{5}$. The yields were calculated based on the limiting reagent (the aldehyde).

HPLC analysis of the isolated mixture of sorbitan acetals revealed the formation of four products (Figure 1). Further analysis by HPLC-MS, ${ }^{1} \mathrm{H}$ and ${ }^{13} \mathrm{C}$ NMR permitted to assign the two first peaks as a pair of diastereoisomers of the sixmembered 3,5-O-acetal (Figure 1, 5a and 5b) and the last two peaks as another pair of diastereoisomers of the five-membered 5,6- $O$-acetal (Figure 1, $\mathbf{4 a}$ and $\mathbf{4 b}$ ). ${ }^{24}$

The nature of the solvent and its influence on the product distribution was next probed. First, the acetalisation of sorbitan (3 equiv) with valeraldehyde ( 1 equiv) in $\mathrm{EtOH}$ in the presence of CSA $(10 \mathrm{~mol} \%)$ gave a mixture of four products in the proportions of 26:17:47:10 (Table 3, Entry 1). Thereby, the ratio between 5,6-O-acetals 4 and 3,5-O-acetals 5 was calculated to $43: 57$ in favour of the six-membered acetals. Replacing EtOH by ${ }^{i} \mathrm{PrOH}$ almost gave a complete conversion (97\%) but the isolated yield dropped to 66\% (Table 3, Entry 2). In toluene, the conversion only reached $81 \%$ and the yield further dropped to $58 \%$ (Table 3, Entry 3). The use of aprotic polar solvents, such as THF and 2-MeTHF permitted to increase the yield of acetals to 98 and $94 \%$, respectively (Table 3, Entries 4 and 5). Interestingly, solvents with very high polarity like $\mathrm{CH}_{3} \mathrm{CN}$ and $\mathrm{DMF}^{25}$ gave lower yields (Table 3, Entries 6 and 7), probably due to the lipophilic character of the aldehyde.

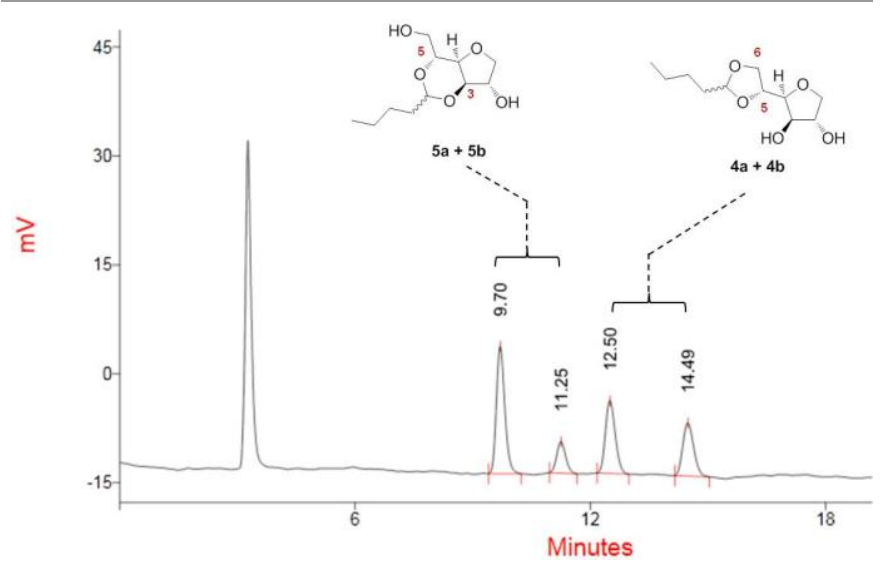

Figure 1. HPLC chromatogram of the mixture of sorbitan acetals (C18 column, refractive index detection) ${ }^{23}$

More importantly, it seems that the ratio between regioisomers 4 and $\mathbf{5}$ is not significantly altered with the nature of the solvent and the six-membered 3,5-O-acetals 5 were recovered as the major regioisomers. However, DMF was found to be an exception, giving predominantly the five-membered 5,6-Oacetals $\mathbf{4}$ as the major regioisomers.

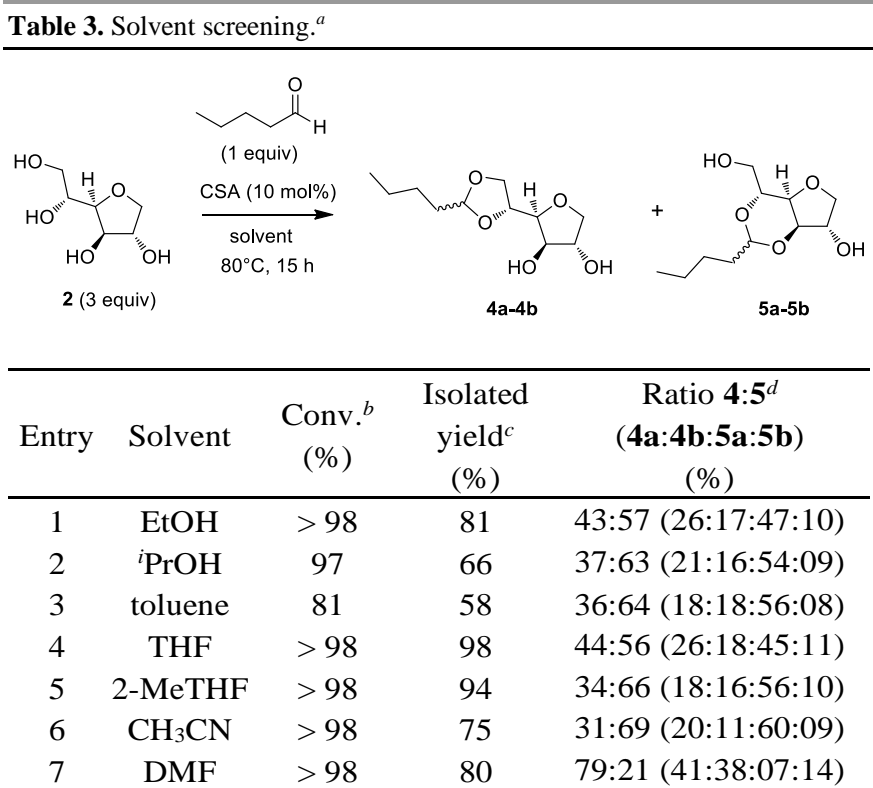

${ }^{a}$ Reaction conditions: $3 \mathrm{mmol}$ of sorbitan, $1 \mathrm{mmol}$ valeraldehyde (1 equiv), CSA $(10 \mathrm{~mol} \%), 1.4 \mathrm{~mL}$ of solvent, $80^{\circ} \mathrm{C}, 15$ hours. ${ }^{b}$ Determined by ${ }^{1} \mathrm{H}$ NMR. ${ }^{c}$ Purification by silica gel chromatography, combined yield of sorbitan acetals $\mathbf{4}$ and $\mathbf{5}$. The yields were calculated based on the limiting reagent (the aldehyde). ${ }^{d}$ Determined by HPLC.

It is important to note that the lack of selectivity is not detrimental from an industrial point of view since mixtures of surfactants are frequently used in formulations.

\section{Sorbitan acetals by transacetalisation}

We have previously identified EtOH and 2-MeTHF as green solvents for the direct acetalisation of sorbitan with valeraldehyde in acidic conditions. However, to date, the high cost of 2-MeTHF could not permit to consider potential industrial applications and EtOH will be much preferred for economic reasons. From a mechanistic point of view, the reaction in $\mathrm{EtOH}$ in the presence of CSA could proceed by direct acetalisation of sorbitan with valeraldehyde and/or through the in-situ formation of a diethylacetal and its subsequent transacetalisation with sorbitan. From this observation, we envisioned that sorbitan acetals could be prepared by transacetalisation of a diethylacetal and EtOH released in this process could be recycled by distillation (Figure 2). 


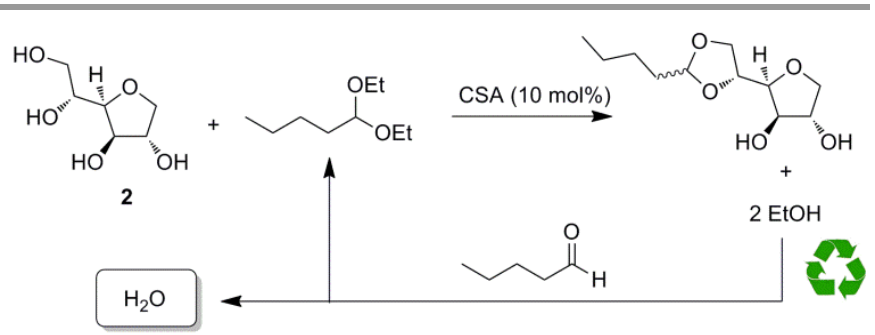

Figure 2. Envisioned process for transacetalisation with sorbitan.

The preparation of sorbitan acetals by transacetalisation was first tested in EtOH. Treatment of 1,1-diethoxypentane (DEP) with 2 equivalents of sorbitan in the presence of CSA (10 mol\%) gave $94 \%$ conversion but only $22 \%$ isolated yield (Table 4, Entry 1). The product was isolated as a 50:50 mixture of 5,6-O- and 3,5-O-regioisomers. When using a stoichiometric amount of sorbitan, the conversion dropped but the yield was slightly improved to $27 \%$ (Table 4, Entry 2). With 2 equivalents of diethoxypentane (DEP), the yield was improved to $49 \%$ and the ratio of regioisomers was hardly altered under these conditions (Table 4, Entry 3). The transacetalisation process was next investigated under solvent-free conditions. With a 1:2 ratio of sorbitan 2 and DEP, a poor yield of $34 \%$ was obtained (Table 4, Entry 4). Surprisingly, the ratio 4:5 was switched in favour of the six-membered 3,5-O-acetals 5 . Finally, the yield was improved to $66 \%$ when using a stoichiometric ratio between 2 and DEP (Table 4, Entry 5).

\begin{tabular}{|c|c|c|c|c|c|c|}
\hline & $\frac{\operatorname{CSA}(10}{\text { solvent, }}$ & & & $\begin{array}{l}\mathrm{HO} \\
4\end{array}$ & $+r^{0}$ & 5 \\
\hline Entry & $\begin{array}{c}\text { Molar ratio } \\
2 \text { : DEP }\end{array}$ & Solvent & $\begin{array}{l}\text { Time } \\
\text { (h) }\end{array}$ & $\begin{array}{c}\text { Conv. }^{c} \\
(\%)\end{array}$ & $\begin{array}{c}\text { Isolated } \\
\text { yield }^{d} \\
(\%)\end{array}$ & 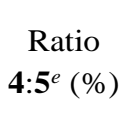 \\
\hline 1 & $2: 1$ & $\mathrm{EtOH}$ & 33 & 94 & 22 & $50: 50$ \\
\hline 2 & $1: 1$ & EtOH & 15 & 77 & 27 & $53: 47$ \\
\hline $3^{b}$ & $1: 2$ & $\mathrm{EtOH}$ & 15 & 63 & 49 & $49: 51$ \\
\hline $4^{b}$ & $1: 2$ & - & 15 & 85 & 34 & $63: 37$ \\
\hline 5 & $1: 1$ & - & 15 & 81 & 66 & $48: 52$ \\
\hline
\end{tabular}

${ }^{a}$ Reaction conditions: $3 \mathrm{mmol}$ of DEP, CSA (10 mol\%), $1.4 \mathrm{~mL}$ of solvent, $80^{\circ} \mathrm{C} .{ }^{b} 3 \mathrm{mmol}$ of sorbitan ${ }^{\mathrm{c}}$ Determined by ${ }^{1} \mathrm{H}$ NMR. ${ }^{d}$ Purification by silica gel chromatography, combined yield of sorbitan acetals $\mathbf{4}$ and $\mathbf{5}$. The yields were calculated based on the limiting reagent: DEP for entries 1-2 and sorbitan for entries 3-5. ${ }^{e}$ Determined by HPLC. DEP $=1,1$-diethoxypentane.

From these results, it appears that the transacetalisation method is particularly attractive under solvent-free conditions, however, the direct acetalisation using aldehyde as alkylating agent in EtOH gave better yields. These conditions have been preferred to further study the scope of the reaction.

\section{Scope of sorbitan acetals}

Optimized conditions were used for the synthesis of aliphatic sorbitan acetals. The direct acetalisation of sorbitan (3 equiv) with a range of linear alkyl aldehydes ( 1 equiv) was performed in the presence of CSA $(10 \mathrm{~mol} \%)$ in $\mathrm{EtOH}$ at $80^{\circ} \mathrm{C}$ for 15 hours (Table 5).
Table 5. Scope of sorbitan acetals by acetalisation
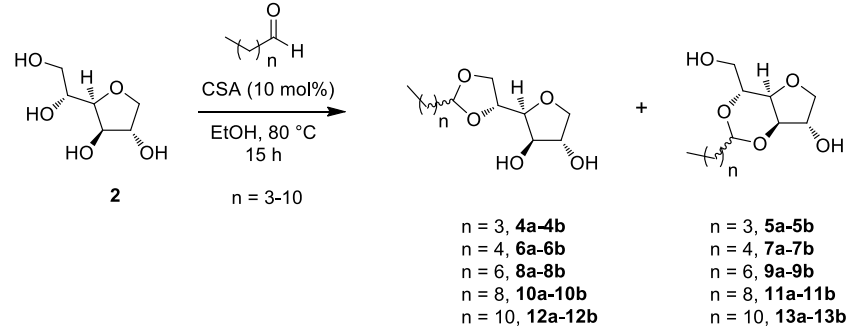

$\mathrm{n}=3,5 \mathrm{a}-5 \mathrm{~b}$

$\mathrm{n}=4,7 \mathrm{a}-7 \mathrm{~b}$

$n=8,11 a-11 b$

$\mathrm{n}=10,13 \mathrm{a}-13 \mathrm{~b}$

\begin{tabular}{|c|c|c|c|c|c|}
\hline Entry & Ald. & $\begin{array}{c}\text { Conv. }{ }^{b} \\
(\%)\end{array}$ & $\begin{array}{c}\text { Isolated } \\
\text { yield }^{c}(\%)\end{array}$ & Acetals & $\begin{array}{c}\text { Product ratio }^{d} \\
(\%) \\
\end{array}$ \\
\hline 1 & pentanal & $>98$ & 81 & $4-5$ & $\begin{array}{c}43: 57 \\
(26: 17: 47: 10)\end{array}$ \\
\hline 2 & hexanal & $>98$ & 58 & $6-7$ & $\begin{array}{c}57: 43 \\
(32: 25: 31: 12)\end{array}$ \\
\hline 3 & octanal & $>98$ & 37 & 8 - 9 & $\begin{array}{c}61: 39 \\
(32: 29: 28: 11)\end{array}$ \\
\hline 4 & decanal & 77 & 32 & $10-11$ & $\begin{array}{c}64: 36 \\
(35: 29: 25: 11)\end{array}$ \\
\hline 5 & dodecanal & 81 & 29 & $12-13$ & $\begin{array}{c}48: 52 \\
(25: 23: 40: 12)\end{array}$ \\
\hline
\end{tabular}

${ }^{a}$ Reaction conditions: $3 \mathrm{mmol}$ of sorbitan, $1 \mathrm{mmol}$ of aldehyde, CSA (10 mol\%), EtOH (1.4 mL), $80{ }^{\circ} \mathrm{C}, 15 \mathrm{~h} .{ }^{b}$ Determined by ${ }^{1} \mathrm{H}$ NMR. ${ }^{c}$ Purification by silica gel chromatography, combined yield of sorbitan acetals. The yields were calculated based on the limiting reagent (the aldehydes). ${ }^{d}$ Determined by HPLC.

The reaction of short alkyl chain aldehydes such as pentanal, hexanal and octanal gave complete conversion while longer alkyl chain aldehydes - decanal and dodecanal - afforded incomplete ones (Table 5, Entries 1-5). Similarly, the isolated yields of the corresponding sorbitan acetals dropped from $81 \%$ with pentanal to $29 \%$ with dodecanal (Table 5, Entries 1-5). These observations could be explained by the difference of polarity between reagents and this effect is more pronounced with long alkyl chain. Finally, a range of sorbitan acetals have been produced by direct acetalisation of sorbitan in EtOH as benign solvent. These compounds could be evaluated as nonionic surfactants with various hydrophilic-lipophilic balances and could be further reduced to the corresponding ethers.

\section{Heterogeneous catalysts screening}

From both economical and environmental points of view, the use of CSA could represent a limitation for this method. Consequently, the possible replacement of CSA by a solid acid catalyst was also investigated. The acetalisation of sorbitan 2 was carried out under the optimized conditions using valeraldehyde, $10 \mathrm{wt} \%$ of a solid acid catalyst in $\mathrm{EtOH}$ at $80^{\circ} \mathrm{C}$ (Table 6). Using a perfluorinated sulfonic acid resin such as Nafion ${ }^{\circledR}$ NR50, the conversion was complete and the corresponding sorbitan acetals 4 and 5 were obtained with 69\% isolated yield (Table 6, Entry 1). Similar results were obtained using Amberlyst A15 dry (Table 6, Entry 2). However, when using Amberlyst A36 dry, the yield of the desired sorbitan monoacetals 4 and 5 decreased to 29\% (Table 6, Entry 3). The use of an acidic zeolite such as H-ZSM-5 ( $\mathrm{Si} / \mathrm{Al}$ ratio $=23$ ), previously calcined at $650^{\circ} \mathrm{C}$ for $3 \mathrm{~h}$, afforded a complete conversion and the desired products were isolated with $73 \%$ yield (Table 6, Entry 4). Finally, the reaction was also feasible 
using a mesoporous silica such as MCM-41 but a lower yield was obtained (Table 6, Entry 5).

\begin{tabular}{|c|c|c|c|c|}
\hline & quiv) & 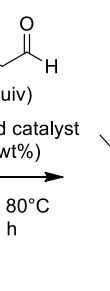 & 4a+4b & 5a+5b \\
\hline Entry & Catalyst & $\begin{array}{c}\text { Conv. }^{b} \\
(\%)\end{array}$ & $\begin{array}{c}\text { Isolated yield }^{c} \\
(\%)\end{array}$ & Ratio $4: 5^{d}(\%)$ \\
\hline 1 & $\begin{array}{c}\text { Nafion }{ }^{\circledR} \\
\text { NR50 }\end{array}$ & $>98$ & 69 & $56: 44$ \\
\hline 2 & $\begin{array}{l}\text { Amberlyst } \\
\text { A15 dry }\end{array}$ & $>99$ & 70 & $49: 51$ \\
\hline 3 & $\begin{array}{l}\text { Amberlyst } \\
\text { A36 dry }\end{array}$ & $>99$ & 29 & $45: 55$ \\
\hline 4 & $\begin{array}{c}\text { Zeolite } \\
\text { H-ZSM-5 }\end{array}$ & $>97$ & 73 & $48: 52$ \\
\hline 5 & MCM-41 & $>99$ & 59 & $46: 54$ \\
\hline
\end{tabular}

${ }^{a}$ Reaction conditions: $3 \mathrm{mmol}$ of sorbitan, $1 \mathrm{mmol}$ of valeraldehyde, solid acid catalyst $(10 \mathrm{wt} \%), 1.4 \mathrm{~mL}$ of EtOH, $80^{\circ} \mathrm{C}, 15 \mathrm{~h} .{ }^{b}$ Determined by ${ }^{1} \mathrm{H}$ NMR. ${ }^{c}$ Purification by silica gel chromatography, combined yield of sorbitan acetals $\mathbf{4}$ and $\mathbf{5}$. The yields were calculated based on the limiting reagent (the aldehyde). ${ }^{d}$ Determined by HPLC.

These results indicate that CSA could be advantageously replaced by a heterogeneous solid acid catalyst. Interestingly, the ratio between five-membered 5,6- $O$-acetals 4 and sixmembered 3,5-O-acetals $\mathbf{5}$ is not significantly altered by the nature of the acid catalyst.

\section{Hydrogenolysis of sorbitan acetals to sorbitan ethers}

We have previously reported the palladium-catalysed reductive cleavage of $\alpha$-D-methyl glucoside acetals to the corresponding ethers using hydrogen as a clean reducing agent. ${ }^{20}$ With sorbitan acetals in hands, we envisioned that applying the previously optimized conditions will furnish the desired sorbitan ethers. ${ }^{26}$ Thus, a mixture of five-membered and sixmembered pentylidene sorbitan acetals $\mathbf{4}$ and $\mathbf{5}$ in cyclopentyl methyl ether (CPME) ${ }^{27}$ was treated under hydrogen pressure (30 bar) in the presence of $5 \%-\mathrm{Pd} / \mathrm{C}(5 \mathrm{~mol} \%)$ at $120^{\circ} \mathrm{C}$ for $15 \mathrm{~h}$ (Table 7).
Table 7. Hydrogenolysis of sorbitan acetals to sorbitan ethers

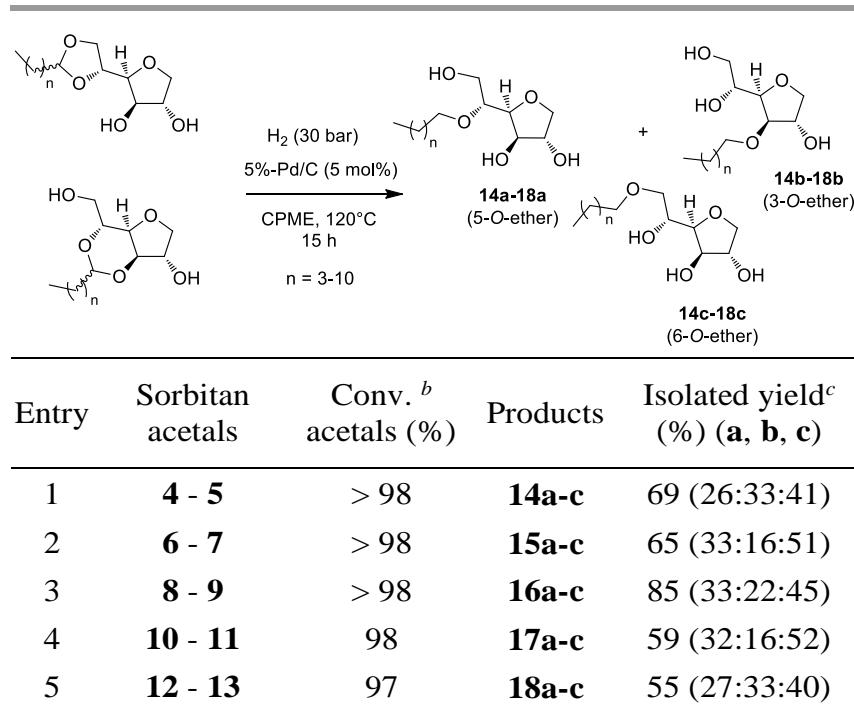

${ }^{a}$ Reaction conditions: $300-\mathrm{mL}$ stainless steel autoclave with mechanical stirrer, mixture of sorbitan acetals $(20 \mathrm{mmol}), 5 \%-\mathrm{Pd} / \mathrm{C}(5 \mathrm{~mol} \%), \mathrm{H}_{2}(30$ bar), CPME (200 mL), $120^{\circ} \mathrm{C}, 15 \mathrm{~h} .{ }^{b}$ Determined by ${ }^{1} \mathrm{H}$ NMR. ${ }^{c}$ Purification by silica gel chromatography, combined yield of sorbitan ethers.

Satisfyingly, the conversions were complete and the corresponding ethers 14a-c were recovered with $69 \%$ isolated yield after purification by column chromatography (Table 7 , Entry 1). As expected from the hydrogenolysis of the mixture of sorbitan acetals, HPLC analysis revealed the formation of 3 regioisomers in the proportions 26:33:41 (Figure 3). Further analysis by $1 \mathrm{D}$ and $2 \mathrm{D}$ NMR permitted to assign the first peak as the 5-O-pentylether $\mathbf{1 4 a}$, the second peak as the 3-Opentylether 14b and the third peak as the 6-O-pentylether 14c by order of elution. Hydrogenolysis of hexylidene 6 and 7 and octylidene $\mathbf{8}$ and $\mathbf{9}$ sorbitan acetals afforded the corresponding sorbitan ethers 15a-c and 16a-c with moderate isolated yields (65-85\%), respectively (Table 7 , Entries 2 and 3 ).

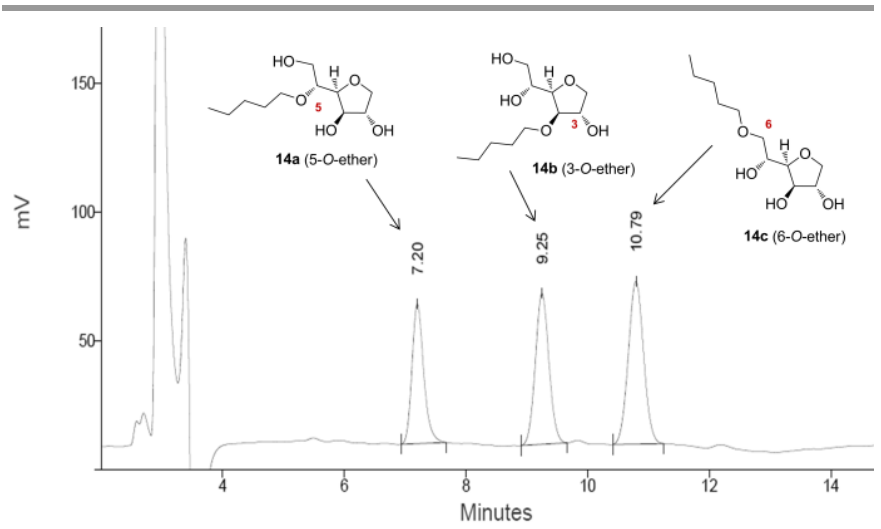

Figure 3. HPLC chromatogram of the mixture of sorbitan ethers 14a-c (C18 column, refractive index detection). ${ }^{28}$

Increasing the alkyl chain length of sorbitan acetals to decylidene and dodecylidene gave lower reactivity and the corresponding sorbitan ethers 17a-c and 18a-c were obtained 
with 59 and $55 \%$ isolated yields, respectively (Table 7, Entries 4-5). It should be noted that the proportions of sorbitan ethers could vary depending on the alkyl chain length but the 6-Oregioisomer has always been formed as the major compound. The mixtures of sorbitan alkyl ethers have been next evaluated as renewable surfactants.

\section{Mechanistic considerations}

In order to get insights on the mechanism of the reductive cleavage of sorbitan acetals to ethers, a pure sample of a 3,5-Opentylidene sorbitan $\mathbf{5 a}$ or $\mathbf{5 b}$ was isolated and submitted to hydrogenolysis [30-mL stainless steel autoclave with magnetical stirrer, hydrogen pressure (30 bar), 5\%-Pd/C (5 mol\%), CPME, $\left.120^{\circ} \mathrm{C}, 15 \mathrm{~h}\right]$. Under these conditions, the conversion reached $69 \%$ and 3-O-pentyl-sorbitan 14b was obtained as the major product with $83 \%$ selectivity (Scheme 3 ). The presence of small amounts of compound $14 \mathrm{c}$ could be attributed to the formation of sorbitan acetals $\mathbf{4 a}$ and/or $\mathbf{4 b}$ by $\mathrm{Pd} / \mathrm{C}$-catalysed scrambling of the acetal function and subsequent hydrogenolysis.

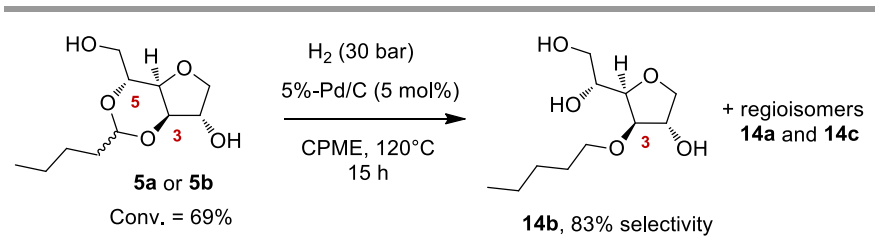

Scheme 3. Hydrogenolysis of a pure sorbitan acetal.

From this result, we propose a mechanism to account for the distribution of products observed. Starting from the 3,5-Opentylidene sorbitans $\mathbf{5 a}$ and $\mathbf{5} \mathbf{b}$, the acetal function could be activated by $\mathrm{Pd}$ with the assistance of the 6-hydroxyl group of the sorbitan moiety (Figure 4a, top). In this configuration, hydrogen could be preferentially delivered to the $\mathrm{C}-\mathrm{O}(5)$ bond that breaks to furnish 3-O-pentylsorbitan $\mathbf{1 4 b}$ as the major regioisomer. By analogy, 5,6- $O$-pentylidene sorbitans $4 \mathbf{a}$ and 4b could coordinate to $\mathrm{Pd}$ with the assistance of the free hydroxyl group at the $\mathrm{O}(3)$-position (Figure 4b, bottom). However, in that case, both $\mathrm{C}-\mathrm{O}(5)$ and $\mathrm{C}-\mathrm{O}(6)$ bonds could be cleaved due to the free rotation around $\mathrm{C}(4)-\mathrm{C}(5)$-bond to give a mixture of 5-O-pentylsorbitan $14 a$ and 6-Opentylsorbitan 14c with almost no selectivity. Assuming that the formation of the 3-O-ethers is almost regioselective, the ratio between 5 - $O$-ethers and 6-O-ethers has been evaluated to around 40:60 based on the a:c ratio for all sorbitan ethers 14-18 (Table 7, Entries 1-5). Finally, these models could explain why all the regioisomers have been obtained with similar proportions.

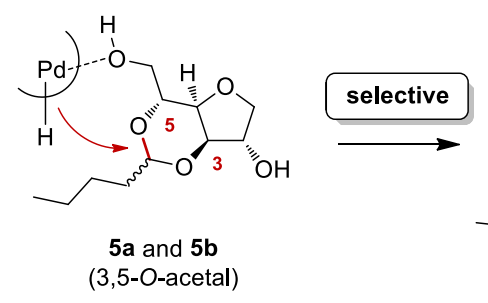

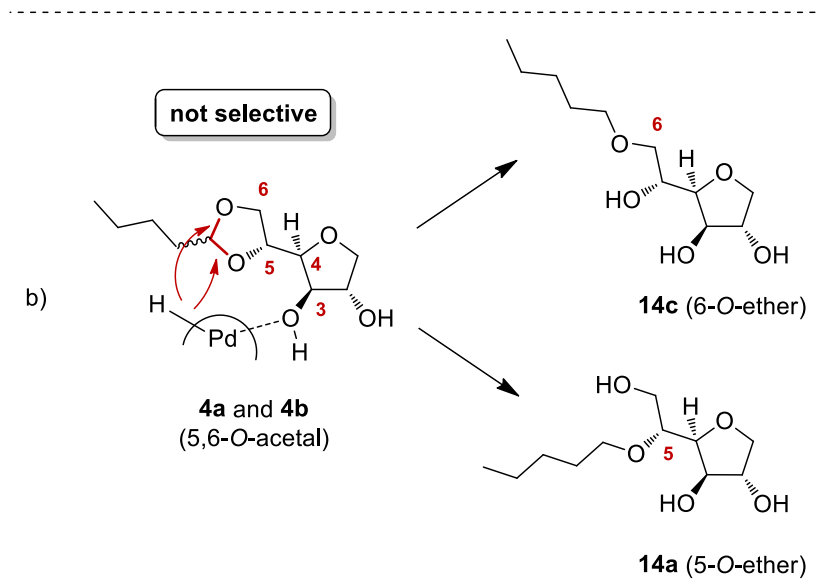

Figure 4. Mechanism proposal for the hydrogenolysis of sorbitan acetals.

\section{Acetalisation / hydrogenolysis sequence}

Having synthesized sorbitan ethers from the corresponding acetals, we envisioned that sorbitan ethers could be directly obtained from sorbitan following an acetalisation / hydrogenolysis sequence without purification of acetal intermediates. Unfortunately, these two steps present some incompatibilities. Indeed, the acetalisation step was carried out in EtOH and requires the presence of an acid catalyst. However, we have previously showed that both EtOH and an acid co-catalyst are deleterious for the hydrogenolysis step, leading to the hydrolysis of acetals. ${ }^{20 a}$ In order to avoid such inconvenience, the acetalisation of sorbitan was performed in the same solvent than the hydrogenolysis step (CPME) and an acid resin was used for easiness of separation. Moreover, $\mathrm{Na}_{2} \mathrm{SO}_{4}$ was used as a dehydrating agent and incorporated at the beginning of the sequence. Thus, sorbitan was treated with valeraldehyde in the presence of Amberlyst 15 (20 wt\%), in CPME at $80^{\circ} \mathrm{C}$ (Table 8). After 15 hours, ${ }^{1} \mathrm{H}$ NMR revealed a conversion of $75 \%$ in aldehyde (Table 8 , Entry 1). The solid acid catalyst was removed by filtration and the crude product was submitted to hydrogenolysis under 30 bar of hydrogen using $5 \%-\mathrm{Pd} / \mathrm{C}(5 \mathrm{~mol} \%)$ at $120^{\circ} \mathrm{C}$ for 15 hours. The conversion of acetals $\mathbf{4 a - b}$ and 5a-b was complete and the desired pentyl sorbitans 14a-c were isolated with $56 \%$ overall yield after purification by column chromatography (Table 8, Entry 1). By comparison, the reductive cleavage of purified sorbitan acetals $\mathbf{4 a - b}$ and $\mathbf{5 a - b}$ gave full conversion and a 53\% isolated yield (Table 8, Entry 2). The same strategy has been applied to a longer alkyl chain such as decanal and the resulting decyl sorbitans $\mathbf{1 7 a - c}$ were obtained with $22 \%$ isolated yield 
without purification of the acetal intermediates (Table 8, Entry 3).

Table 8 Hydrogenolysis of crude sorbitan acetals ${ }^{a}$

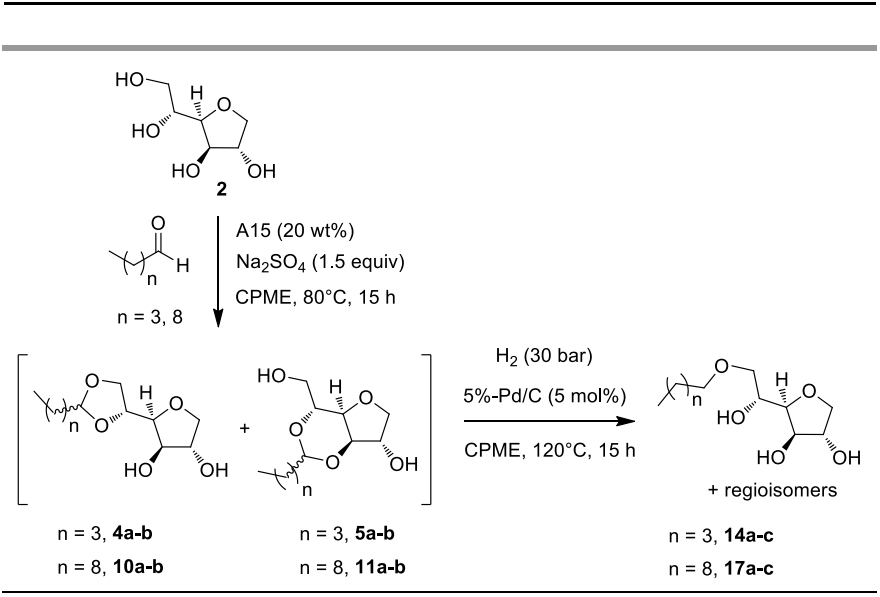

\begin{tabular}{ccccccc}
\hline Entry & $\mathrm{n}$ & $\begin{array}{c}\text { Conv. } \\
\text { ald. }(\%)\end{array}$ & $\begin{array}{c}\text { Purif. } \\
\text { acetals }\end{array}$ & $\begin{array}{c}\text { Conv. }^{b} \\
\text { acetals }(\%)\end{array}$ & $\begin{array}{c}\text { Sorbitan } \\
\text { ethers }\end{array}$ & $\begin{array}{c}\text { Isolated } \\
\text { yield }^{c} \\
(\%)\end{array}$ \\
\hline 1 & 3 & 75 & No & $>98$ & 14a-c & 56 \\
2 & 3 & - & Yes & $>98$ & 14a-c & 53 \\
3 & 8 & 24 & No & $>98$ & $\mathbf{1 7 a - c}$ & 22 \\
4 & 8 & - & Yes & 97 & 17a-c & 21
\end{tabular}

${ }^{a}$ Reaction conditions: Sorbitan (60 mmol, 2 equiv), aldehyde ( $30 \mathrm{mmol}, 1$ equiv), $\mathrm{A} 15$ (20 wt $\%$ ), $\mathrm{Na}_{2} \mathrm{SO}_{4}$ (1.5 equiv), CPME, $80^{\circ} \mathrm{C}, 15 \mathrm{~h}$ then, $5 \%$-Pd/C (5 mol\%), $\mathrm{H}_{2}(30 \mathrm{bar}), \mathrm{CPME}, 120^{\circ} \mathrm{C}, 15 \mathrm{~h}$ in a $500-\mathrm{mL}$ stainless steel autoclave with mechanical stirrer. ${ }^{b}$ Determined by ${ }^{1} \mathrm{H}$ NMR. ${ }^{c}$ Purification by silica gel chromatography, combined yield of all ether regioisomers. Overall yields are given from sorbitan and are calculated based on the limiting reagent (the aldehyde).

Once again, a similar result (21\% yield) was obtained when using purified acetals 10a-b and 11a-b (Table 8, Entry 4). Finally, these experiments have shown that the hydrogenolysis could be directly performed on the crude reaction mixture as similar results were obtained with or without purification of the acetals. These conditions could be advantageous for the large scale production of sorbitan ethers.

\section{Acetalisation/transacetalisation cascade}

The preparation of sorbitan ethers from sorbitan by an acetalisation/hydrogenolysis sequence is mainly limited by the acetalisation step. This is particularly true for the synthesis of sorbitan ethers bearing a long alkyl chain due to the great difference of polarity between starting materials (sorbitan and fatty aldehyde). In order to improve the yield of these long chain sorbitan acetals, an acetalisation/transcetalisation cascade was designed using short chain aldehyde as "solubility relay" (Figure 5). ${ }^{29}$ In this strategy, short chain sorbitan acetals could be formed in the sorbitan polar phase and migrate in the nonpolar phase to undergo trans-acetalisation with a long chain aldehyde to give the desired long chain sorbitan acetals.

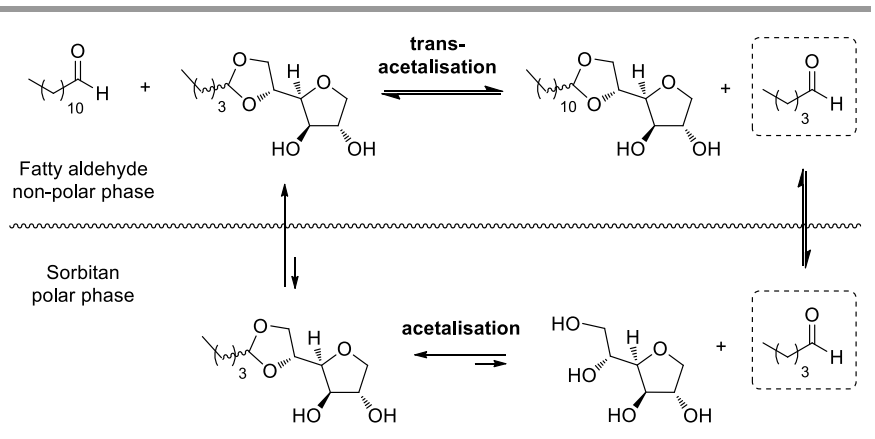

Figure 5. Principle of the acetalisation/transcetalisation cascade using short chain aldehyde as "solubility relay".

The viability of this concept was first investigated in homogeneous conditions. Thus, sorbitan was treated with valeraldehyde ( 0.5 equiv) in $\mathrm{CPME}$ at $80^{\circ} \mathrm{C}$ for $3 \mathrm{~h}$ to give the corresponding sorbitan acetals 4a-b and 5a-b. Transacetalisation with dodecanal ( 0.5 equiv) gave a $46: 54$ mixture of pentylidene- $\mathbf{4 a - b}$ and $\mathbf{5 a - b}$ and dodecylideneacetals 12a-b and 13a-b (Table 9, Entry 1). The yield of dodecylidene sorbitan has been calculated to $58 \%$ based on the overall mass recovered and the HPLC ratio. By comparison, the direct acetalisation of sorbitan with dodecanal in CPME gave only $24 \%$ isolated yield of the desired product (Table 9, Entry 2). The phenomenon is even more pronounced under solvent-free conditions. The previous yield of $36 \%$ obtained by direct acetalisation increased to $82 \%$ using this cascade procedure (Table 9, Entries 3-4).

Table 9. Acetalisation/transacetalisation cascade ${ }^{a}$

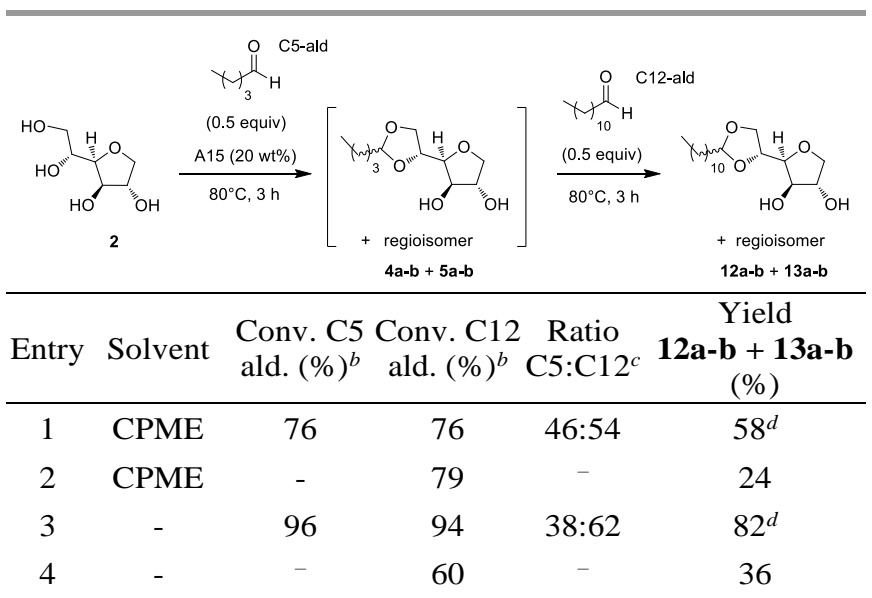

${ }^{a}$ Reaction conditions: sorbitan ( 1 equiv), valeraldehyde (30 mmol, 0.5 equiv), A15 (20 wt $\%)$, dry CPME ( $30 \mathrm{~mL}), \mathrm{Na}_{2} \mathrm{SO}_{4}\left(0.75\right.$ equiv), $80^{\circ} \mathrm{C}, 3 \mathrm{~h}$; then, dodecanal $\left(30 \mathrm{mmol}, 0.5\right.$ equiv), $80^{\circ} \mathrm{C}, 3 \mathrm{~h} .{ }^{b}$ Conversions were determined by ${ }^{1} \mathrm{H}$ NMR. ${ }^{c}$ Ratio of sorbitan acetals were determined by HPLC. ${ }^{d}$ Calculated based on the overall mass recovered and the $\mathrm{C} 5 / \mathrm{C} 12$ HPLC ratio and based on the limiting reagent (dodecanol).

\section{Amphiphilic properties}

The surface tension of aqueous solutions of the mixtures of sorbitan acetals (abbreviated CxAcSorb, with $\mathrm{x}=$ number of carbons of the alkyl chain, Ac = acetal, Sorb = sorbitan) were first measured by the Wilhelmy plate method using a platinum 
rod as probe (Figure 6). All sorbitan acetals induce a strong decrease of the surface tension of water to a plateau value of about $30 \mathrm{mN} \cdot \mathrm{m}^{-1}$.

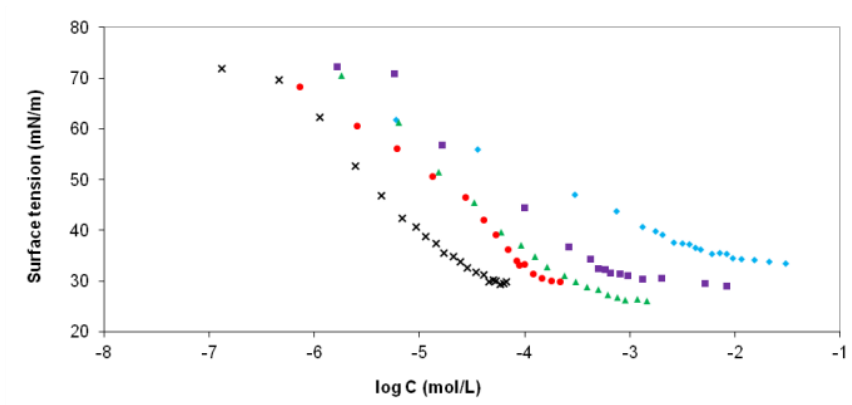

Figure 6. Surface tension vs. concentration of sorbitan acetals.

×C12AcSorb, •C10AcSorb, $\triangle$ C8AcSorb, $₫$ C6AcSorb $\bullet$ C5AcSorb

However, quite different profiles are observed depending on the alkyl chain length, C8 to C12 sorbitan acetals exhibit typical surfactant profiles with poorly defined CMC appearing at low concentrations whereas C5 and C6 sorbitan acetals display a smoother decrease and a plateau value at quite high concentrations (Table 10). These later profiles are typical of short chain amphiphiles exhibiting behaviour of hydrotropes which have no CMC since they cannot form true micelles. Instead, they give small aggregates above an ill-defined Minimum Aggregation Concentrations (MAC).

Table 10. Critical micellar concentrations (CMC) and minimum aggregation concentrations (MAC) of sorbitan acetals.

\begin{tabular}{ccccc}
\hline Entry & Sorbitan acetals & $\begin{array}{c}\text { Ratio }^{a} \\
(\%)\end{array}$ & $\begin{array}{c}\mathrm{CMC}^{2} \text { MAC } \\
(\mathrm{mmol} / \mathrm{L})\end{array}$ & $\begin{array}{c}\gamma \\
(\mathrm{mN} / \mathrm{m})^{b}\end{array}$ \\
\hline 1 & C5AcSorb & $43: 57$ & 6.3 & 35 \\
2 & C6AcSorb & $57: 43$ & 0.51 & 32 \\
3 & C8AcSorb & $61: 39$ & 0.29 & 28 \\
4 & C10AcSorb & $64: 36$ & 0.12 & 30 \\
5 & C12AcSorb & $50: 50$ & 0.034 & 30
\end{tabular}

${ }^{a}$ Ratio of five-membered and six-membered regioisomers were determined by HPLC. ${ }^{b}$ Determined by tensiometry.

Sorbitan acetals bearing a short C5 or C6 alkyl chain are less efficient than their longer chain counterparts (Table 10, Entries 1-2). Nevertheless, these compounds could present valuable properties since they facilitate the solubilisation of high concentrations of hydrophobic compounds in water without forming viscous liquid crystals unlike true surfactants. ${ }^{30}$ C8AcSorb was found to be the best compound to reduce the surface tension of water with a saturated value of $28 \mathrm{mN} / \mathrm{m}$ but its MAC $(0.29 \mathrm{mmol} / \mathrm{L})$ is too high to be interesting for surfactant applications (Table 10, Entry 3). Further increasing the alkyl chain length to $\mathrm{C} 10$ and $\mathrm{C} 12$ permitted to decrease the MAC to 0.12 and $0.034 \mathrm{mmol} / \mathrm{L}$, respectively (Table 10, Entries 4-5). Moreover, both compounds exhibit a saturated value of $30 \mathrm{mM} / \mathrm{m}$ that makes them good candidates as biobased surfactants.
Similarly, the amphiphilic properties of sorbitan ethers (abbreviated CxEthSorb, with $\mathrm{x}=$ number of carbons of the alkyl chain, Eth $=$ ether, Sorb $=$ sorbitan) were next investigated. Again, all sorbitan ethers allow the reduction of the surface tension of water and a plateau value is reached for each compound above a characteristic concentration (Figure 7).

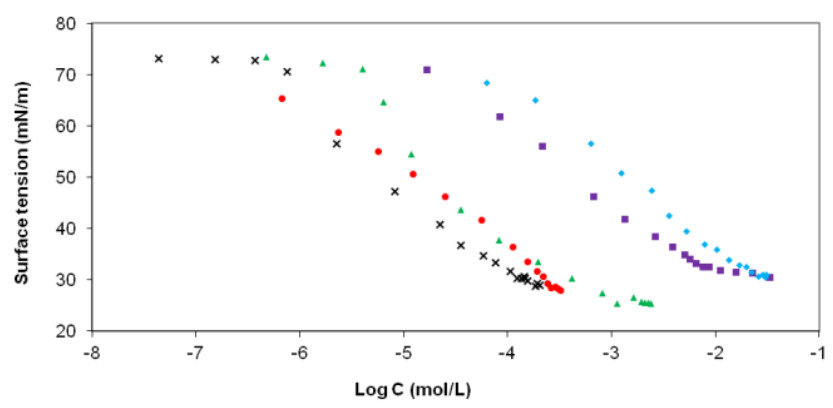

Figure 7. Surface tension vs. concentration of sorbitan ethers.

$\times$ C12EthSorb, $\bullet$ C10EthSorb, $\triangle$ C8EthSorb, $\quad$ C6EthSorb, $\rightarrow$ C5EthSorb.

The reduction of surface tension with concentration is even smoother than what was observed in the case of acetals, which could be due to the presence of mixtures of isomers. However, it allows defining CMC or MAC values for each chain length and again, a distinction can be made between compounds selfassociating at quite high concentrations (C5, C6, C8) and those being closer in behaviour to true surfactants (C10 and C12). The CMC/MAC values determined from the curves are summarized in table 11 .

Table 11. Critical micellar concentrations (CMC) and minimum aggregation concentrations (MAC) of sorbitan ethers.

\begin{tabular}{ccccc} 
Entry & $\begin{array}{c}\text { Sorbitan } \\
\text { ethers }\end{array}$ & $\begin{array}{c}\text { Ratio a:b:c } \\
(\%)\end{array}$ & $\begin{array}{c}\text { CMC/MAC }^{b} \\
(\mathrm{mmol} / \mathrm{L})\end{array}$ & $\begin{array}{c}\gamma \\
(\mathrm{mN} / \mathrm{m})^{b}\end{array}$ \\
\hline 1 & C5EthSorb & $26: 33: 41$ & 7.6 & 32 \\
2 & C6EthSorb & $33: 16: 51$ & 20.9 & 30 \\
3 & C8EthSorb & $33: 22: 45$ & 0.59 & 26 \\
4 & C10EthSorb & $32: 16: 52$ & 0.35 & 28 \\
5 & C12EthSorb & $27: 33: 40$ & 0.091 & 30
\end{tabular}

${ }^{a}$ Determined by HPLC. ${ }^{b}$ Determined by tensiometry.

As expected, the CMC/MAC of sorbitan ethers decreases gradually with the increase of the alkyl chain length, from 7.6 $\mathrm{mmol} / \mathrm{L}$ for C5EthSorb to $0.091 \mathrm{mmol} / \mathrm{L}$ for C12EthSorb (Table 11, Entries 1-5). Interestingly, the reduction of the surface tension of water is slightly better for sorbitan ethers compared to the corresponding acetals (Table 11, Entries 1-5). It should also be pointed out that for a given chain length, CMCs/MACs are higher for sorbitan ethers than for their acetal counterparts, which shows the hydrophilic contribution of the hydroxyl group released during the cleavage of sorbitan acetals to ethers. The mixture of C6EthSorb exhibits an unexpected high MAC value (Table 11, Entry 2), which could be due to a different ratio between regioisomers. Indeed, one can expect 
that regioisomeric effects have a great impact on the amphiphilic properties of these compounds, as already observed in the case of isosorbide ethers. ${ }^{31}$ Comparing the MAC values of C5AcSorb $(6.3 \mathrm{mmol} / \mathrm{L})$ and C5EthSorb $(7.6$ $\mathrm{mmol} / \mathrm{L})$ to that of the 5-O-monopentyl ether of isosorbide $(\mathrm{C} 5 \text { EthIso, } 230 \mathrm{mmol} / \mathrm{L})^{32}$ and the 1-O-monopentyl ether of glycerol (C5EthGly, $250 \mathrm{mmol} / \mathrm{L})^{33}$ shows that the short-chain sorbitan acetals and ethers could be used as particularly efficient hydrotropes.

In order to rank the effectiveness of these new surfactants, the two longest compounds, namely dodecylidenesorbitan (C12AcSorb) and dodecylsorbitan (C12EthSorb), were compared to commercially available surfactants and other benchmarks (Table 12). Only compounds bearing a C12 alkyl chain have been selected for better comparison. With CMCs of 0.034 and $0.091 \mathrm{mmol} / \mathrm{L}$ respectively, $\mathrm{C} 12$ sorbitan acetal and ether exhibit similar performance than the synthesized ${ }^{34} \mathrm{C} 12$ sorbitan ester (Table 12, Entries 1-3). Moreover, their performances are also close to those of commercially available Span $20{ }^{\circledR}$ which is an industrial product with a mixture of various alkyl chain lengths (Table 12, Entry 4). These results validate our approach that ester surfactants could be replaced with similar molecules bearing an ether function without significant loss of activity. Their improved stability towards hydrolysis could potentially widen the scope of applications of these sorbitan-based surfactants.

Table 12. Comparison of Critical Micelle Concentration (CMC).

\begin{tabular}{|c|c|c|c|c|}
\hline Entry & Surfactant & $\mathrm{HLB}^{a}$ & $\begin{array}{c}\mathrm{CMC}^{b} \\
(\mathrm{mmol} / \mathrm{L})\end{array}$ & $\begin{array}{c}\gamma \\
(\mathrm{mN} / \mathrm{m})^{b}\end{array}$ \\
\hline
\end{tabular}

1

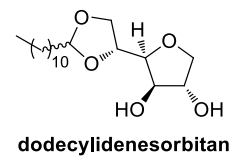

(mixture of regioisomers)

2

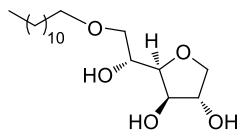

dodecylsorbitan (mixture of regioisomers)

3

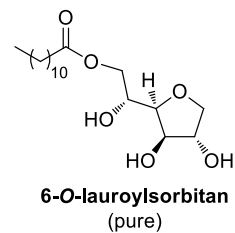

4

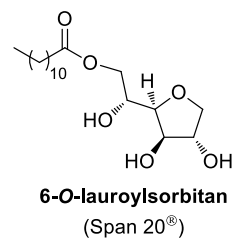

${ }^{a}$ Calculated with the Griffin method. ${ }^{b}$ Determined by tensiometry.

\section{Conclusions}

In conclusion, we have developed cheap and environmentally friendly ${ }^{35}$ access to sorbitan ethers through hydrogenolysis of the corresponding acetals. These acetals were prepared by direct acetalisation or transacetalisation of sorbitan using aldehydes or their corresponding diethylacetals and were isolated with moderate to good yields (29-81\%). It has been shown that these sorbitan acetals exist as a mixture of fivemembered and six-membered regioisomers. The hydrogenolysis of the mixtures gave the corresponding sorbitan ethers as a mixture of 3 regioisomers with $55-85 \%$ isolated yields. In order to avoid the isolation of sorbitan acetals, an acetalisation/hydrogenolysis sequence has been optimized giving the corresponding ethers with similar isolated yields. Moreover, an acetalisation/transacetalisation cascade has been developed to increase the yield of the limiting step (acetalisation) using a mixture of short and long chain aldehydes. Finally, the physico-chemical properties have been determined for all sorbitan derivatives. Both C12 sorbitan acetals and ethers exhibit surfactant properties with similar performance than commercially available Span 20®. These new surfactants could find applications in processes or products requiring to work under (strong) acid or basic conditions.

\section{Experimental}

\section{General information}

Sorbitol 1 (> 98\% purity) was purchased from Sigma-Aldrich. Valeraldehyde, hexanal, octanal, decanal and dodecanal were supplied by Sigma-Aldrich or Alfa-Aesar. Amberlyst 15 dry and Amberlyst 36 were bought from Rohm and Haas. Pd/C (5 or $10 \%, \mathrm{Pd}$ on activated carbon, reduced and dry, Escat 1431) was purchased from Strem Chemicals. All other reagents and solvents were used as received without further purification. See Supporting Information for further details.

General procedure for the preparation of sorbitan acetals: In a round bottom flask equipped with a condenser fitted with a $\mathrm{CaCl}_{2}$ guard, under an argon atmosphere, 1,4-D-sorbitan 2 (5.00 g, $30.5 \mathrm{mmol}, 3$ equiv) was dissolved in dry EtOH. The aldehyde (10.2 mmol, 1 equiv) was added dropwise, followed by camphorsulfonic acid ( $10 \mathrm{wt} \%$ / aldehyde). Then, the mixture was magnetically stirred at $80^{\circ} \mathrm{C}$ for 15 hours. The mixture was cooled down to room temperature and the solvent was evaporated under reduced pressure. The residue was triturated in EtOAc and the excess of sorbitan was filtered off and washed with cold EtOAc. This operation was repeated in order to remove any traces of sorbitan. The residue was concentrated and purified by flash chromatography to give the desired sorbitan acetals as a mixture of 5,6- $O$-alkylidene- and 3,5-O-alkylidene-1,4-D-sorbitan regioisomers. Each regioisomer was obtained as a mixture of diastereoisomers. The ratio of compounds has been determined by HPLC. 
General procedure for the preparation of sorbitan ethers: The mixture of 1,4-D-sorbitan acetals $(20 \mathrm{mmol})$ was diluted in dry CPME (200 mL) and 5\%-Pd/C (1.00 g, $5 \mathrm{~mol} \%$ in $\mathrm{Pd})$ was added in a $300-\mathrm{mL}$ stainless steel autoclave. The reactor was tightly closed, purged three times with hydrogen and hydrogen pressure was introduced (30 bar). The system was heated at $120^{\circ} \mathrm{C}$ and mechanically stirred for 15 hours. After cooling to room temperature, hydrogen pressure was released and the reaction mixture was then dissolved in absolute EtOH (100 $\mathrm{mL}$ ) and filtered (Millipore Durapore filter $0.01 \mu \mathrm{m}$ ). The filtrate was evaporated under reduced pressure and the residue was purified by flash chromatography to give sorbitan ethers as mixtures of 3 regioisomers. The ratio of compounds has been determined by HPLC.

General procedure for the surface tension measurements: The surface tensions were measured at room temperature $(23 \pm 1)^{\circ} \mathrm{C}$ with a K100MK2 Krüss tensiometer using a platinum rod as a probe. Measurements were made on $2.5 \mathrm{~mL}$ samples. The surface tension of pure water was first measured and the concentration was then gradually increased while keeping a constant sample volume. When the surface tension was stable (standard deviation of the 5 final measurements lower than 0.1 $\mathrm{mN} / \mathrm{m}$ ), a precise volume of the solution was removed and the same volume of a concentrated stock solution was added under stirring. For a given compound, the measurement was stopped once the surface tension no longer decreased while increasing the concentration.

\section{Acknowledgments}

The authors would like to thank the company TEREOS SYRAL SAS and the Association Nationale de la Recherche et de la Technologie (ANRT) for financial support through a CIFRE grant (2011/1660) for C.G. The team of $\operatorname{Pr} \mathrm{Z}$. Mouloungui at ENSIACET-Toulouse is acknowledged for preliminary determination of amphiphilic properties of sorbitan acetals. Pr Y. Queneau at INSA-Lyon is also acknowledged for fruitful discussion on the structure of sorbitan acetals. Finally, the authors would like to thank one of the reviewers for helpful suggestions on the mechanism proposal.

\section{Notes and references}

${ }^{a}$ Equipe CAtalyse, SYnthèse et ENvironnement (CASYEN), Institut de Chimie et Biochimie Moléculaires et Supramoléculaires (ICBMS), UMR 5246 CNRS, Université Claude Bernard Lyon 1, 43 boulevard du 11 novembre 1918, Bât. Curien/CPE, 69622, Villeurbanne, France.

$b$ Laboratoire de Chimie Moléculaire et Formulation, E.A. 4478, Université Lille Nord de France, USTL, ENSCL, Cité Scientifique, 59652 Villeneuve d'Ascq Cedex, France.

c Tereos Syral SAS, Z.I et Portuaire B.P.32, 67390 Marckolsheim, France.

$\dagger$ Footnotes should appear here. These might include comments relevant to but not central to the matter under discussion, limited experimental and spectral data, and crystallographic data.
Electronic Supplementary Information (ESI) available: [details of any supplementary information available should be included here]. See DOI: $10.1039 / \mathrm{c} 000000 \mathrm{x} /$

1 a) P. Foley, A. Kermanshahi pour, E. S. Beach and J. B. Zimmerman, Chem. Soc. Rev., 2012, 41, 1499-1518. b) K. Hill, in Surfactants from Renewable Resources, ed. M. Kjellin and I. Johansson, John Wiley \& Sons, Ltd., 2010.

2 M. Capderou and P. Pale, C. R. Chimie, 2004, 7, 607-610.

3 F. W. Lichtenthaler and S. Peters, C. R. Chimie, 2004, 7, 65-90.

4 D. K. Allen and B. Y. Tao, J. Surfact. Deterg., 1999, 2, 383-390.

5 Y. Queneau, S. Chambert, C. Besset and R. Cheaib, Carbohyd. Res., 2008, 343, 1999-2009.

6 W. Von Rybinski and K. Hill, Angew. Chem. Int. Ed., 1998, 37, 1328-1345.

7 J. Giacometti, N. Wolf, Z. Gomzi and C. Milin, React. Kinet. Catal. Lett., 1996, 59, 235-240.

8 A. Ducret, A. Giroux, M. Trani and R. Lortie, J. Am. Oil Chem. Soc., 1996, 73, 109-113.

9 L. J. Peltonen and J. Yliruusi, J. Colloid Int. Sc., 2000, 227, 1-6.

10 a) R. Strickley, Pharm. Res., 2004, 21, 201-230. b) A. Kato and I. Shibasaki, J.Antibacter. Antifung. Agents, 1975, 8, 355-361.

11 a) H. Maag, J. Am.Oil. Chem. Soc., 1984, 61, 259-267. b) J. P. Houlmont, K. Vercruysse, E. Perez, I. Rico-Lattes, P. Bordat and M. Treilhou, Int. J. Cosmetic Sci., 2001, 23, 363-368.

12 W. L. Kubie, J. L. O'Donnell, H. M. Teeter and J. C. Cowan, J. Am. Oil Chem. Soc, 1963, 40, 105-107.

13 J. I. Garcia, E. Pires, L. Aldea, L. Lomba, E. Perales and B. Giner, Green Chem., 2015, 17, 4326-4333.

14 For selected examples, see: a) L. Vanbaelinghem, P. Gode, G. Goethals, P. Martin, G. Ronco and P. Villa, Carbohydr. Res., 1998, 311, 89-94. b) R. Miethchen, J. Holtz and H. Prade, Tetrahedron, 1992, 48, 3061-3068. c) A. L. Raymond and E. F. Schroeder, J. Am. Chem. Soc., 1948, 70, 2785-2791. d) A. Smith, P. Nobmann, G. Henehan, P. Bourke and J. Dunne, Carbohydr. Res., 2008, 343, 2557-2566. e) P. Nobmann, P. Bourke, J. Dunne and G. Henehan, J. Appl. Microbiol., 2010, 108, 2152-2661. f) P. Nobmann, A. Smith, J. Dunne, G. Henehan and P. Bourke, Int. J. Food Microbiol., 2009, 128, 440-445.

15 For reviews, see: a) M. Sutter, E. Da Silva, N. Duguet, Y. Raoul, E. Métay and M. Lemaire, Chem. Rev., 2015, 115, 8609-8651. b) M. Sauthier, A. Mortreux and I. Suisse, Carbohydr. Res., 2014, 40, 73-98.

16 M. L. Tulchinsky, S.-s. Ng and C. L. Rand, 2012, WO 2012/148530.

17 For $N$-alkylation, see: a) F. Fache, L. Jacquot and M. Lemaire, Tetrahedron Lett., 1994, 35, 3313-3314. b) F. Fache, F. Valot, A. Milenkovic and M. Lemaire, Tetrahedron, 1996, 52, 9777-9784. c) T. Mohy El Dine, S. Chapron, M.-C. Duclos, N. Duguet, F. Popowycz and M. Lemaire, Eur. J. Org. Chem., 2013, 24, 54455454.

18 For $O$-alkylation, see: a) V. Bethmont, F. Fache and M. Lemaire, Tetrahedron Lett., 1995, 36, 4235-4236. b) F. Fache, V. Bethmont, L. Jacquot and M. Lemaire, Recl. Trav. Chim. Pays-Bas, 1996, 115, 231-238.

19 a) Y. Shi, W. Dayoub, A. Favre-Réguillon, G.-R. Chen and M. Lemaire, Tetrahedron Lett., 2009, 50, 6891-6893. b) Y. Shi, W. 
Dayoub, G.-R. Chen and M. Lemaire, Green Chem., 2010, 12, 21892195. c) Y. Shi, W. Dayoub, G.-R. Chen and M. Lemaire, Sci. China Chem., 2010, 53, 1953-1956. d) M. Sutter, W. Dayoub, E. Métay, Y. Raoul and M. Lemaire, ChemSusChem., 2012, 5, 2397-2309. e) M. Sutter, W. Dayoub, E. Métay, Y. Raoul and M. Lemaire, Green Chem., 2013, 15, 786-797.

20 a) C. Gozlan, R. Lafon, N. Duguet, A. Redl and M. Lemaire, RSC $A d v ., 2014,4$, 50653-50661. b) Y.-J. Zhang, W. Dayoub, G.-R. Chen and M. Lemaire, Eur. J. Org. Chem., 2012, 10, 1960-1966.

21 Sorbitol has been identified as one of the top value added chemicals from biomass, see: T. Werpy and G. Petersen in Top Value Added Chemicals from Biomass. Results of Screening for Potential Candidates from Sugars and Synthesis Gas, Vol. 1, US Department of Energy, 2004. Moreover, the worldwide production of sorbitol reaches 650,000 tons per year and its low price (about 0.7 euros $/ \mathrm{Kg}$ ) makes it an ideal renewable platform molecule.

22 J. E. Holladay, J. Hu, Y. Wang and T. A. Werpy, patent US20070173651, 2007.

23 See Supporting Information for detailed HPLC conditions.

24 See supporting Information for the assignment of each compound by HPLC-MS and ${ }^{1} \mathrm{H}$ and ${ }^{13} \mathrm{C}$ NMR.

25 DMF has been tested for comparison purposes as it is traditionally used in carbohydrate chemistry for the solubilization of highly polar species.

26 It has been previously shown that the reaction could not be carried out in ethanol due to the formation of transacetalisation products, leading to ethoxyalkanes after hydrogenolysis.

27 For the green credentials of CPME, see: a) K. Watanabe, N. Yamagiwa and Y. Torisawa, Org. Process Res. Dev., 2007, 11, 251258. b) K. Watanabe, Molecules, 2013, 18, 3183-3194. c) V. Antonucci, J. Coleman, J. B. Ferry, N. Johnson, M. Mathe, J. P. Scott and J. Xu, Org. Process Res. Dev., 2011, 15, 939-941. For recent example of application, see: d) U. Azzena, M. Carraro, A. D. Mamuye, I. Murgia, L. Pisano and G. Zedde, Green Chem., 2015, 17, 3281-3284. e) A. Mouret, L. Leclercq, A. Mühlbauer and V. Nardello-Rataj, Green Chem., 2014, 16, 269-278. f) K. Skowerski, J. Biatecki, A. Tracz and T. K. Olszewski, Green Chem., 2014, 16, 1125-1130.

28 See Supporting Information for detailed HPLC conditions.

29 A similar strategy is used for the synthesis of APGs in which butanol serves as short chain alcohol for the glycosylation of glucose. The intermediate then undergoes trans-glycosylation with longer chain alcohols to give the corresponding APGs. For example, see: K. Hill, Pure Appl. Chem., 2000, 72, 1255-1264 and reference 6.

30 V. Molinier and J.-M. Aubry, Carbohydr. Res., 2014, 40, 51-72.

31 Y. Zhu, V. Molinier, M. Durand, A. Lavergne and J.-M. Aubry, Langmuir 2009, 25, 13419-13425.

32 Y. Zhu, M. Durand, V. Molinier and J.-M. Aubry, Green Chem. 2008, 10, 532-540.

33 L. Moity, Y. Shi, V. Molinier, W. Dayoub, M. Lemaire and J.-M. Aubry, J. Phys. Chem. B, 2013, 117, 9262-9272.

34 See Supporting Information for details on the synthesis of dodecanoylsorbitan.

35 See Supporting Information for a discussion about the economical and environmental aspects of this route to sorbitan ethers. 